It will be seen that the chief component is lichenin $\left(\mathrm{C}_{12} \mathrm{H}_{20} \mathrm{O}_{10}\right)$, a starch-like body which consists of two elements soluble in hot water, one of which is also soluble in cold water. There is a small quantity of soluble gum and 36 per cent. of a substance partially extracted by boiling water called amylaceous fibrin. Cetrarin is a bitter principle, readily extracted by hot water, and gives the characteristic taste to the decoction, and was probably valued as a bitter tonic.

Thus Iceland moss affords the necessary material for lubricating and soothing the mucous membrane with which it comes in contact. This quality is amply realised in the discs called " lichenoids," perfected by Mr. Martindale, who has excluded the cetrarin. They are of a size and consistence suitable for slow and passive solution in the mouth, a process by which the demulcent and lubricating properties are better obtained than by the ordinary soft jujube, which encourages rapid mastication and active deglutition. They will be found satisfactory in inflammatory and excitable states of fauces and oropharynx, especially to speakers who suffer with dry mouth and throat. As a sialogogue Iceland moss is an excellent corrective in pyrosis.

\title{
Austracts.
}

\section{FAUCES AND PHARYNX.}

McCollom, J. H. (Boston).-The Experience of Nine Years in the Treatment of Diphtheria with Antitoxin. "Boston Med. and Surg. Journ.," June 1, 1905.

A long article with numerous statistics, the conclusions being: First, that antitoxin is a remedial agent of immense value in the treatment of diphtheria, and should be classed among the great medical discoveries of the nineteenth century. Second, that in order to obtain the best results it is important that the serum should be given at the earliest possible moment in the course of the disease. Third, that in attacks of diphtheria of a severe type antitoxin should be given in very large doses. Fourth, that in laryngeal diphtheria, in the majority of instances, intubation is the operation of election.

Macleod Yearsley.

Langmaid, S. W. (Boston).-The Effects of Tobacco upon the Throat. "Boston Med. and Surg. Journ.," June 15, 1905.

The author's experience of the evil effects of tobacco-smoking on the throat has been contrary to the general teaching of the text-books. He acknowledges that his observations, made in a cold, moist climate, may not hold good in warmer or warm-moist ones. He believes that in all cases of acute and chronic naso-pharyngitis smoking must be abandoned, or the cure is delayed.

He believes that tobacco acts less by the irritation to the pharyngeal mucosa by the smoke than by its poisonous effects upon the nervous system, whereby vaso-motor disturbances are set up.

The author quotes de Schweinitz and Edsall, Wyatt Wingrave, Petity and others as offering sufficient evidence of the pcisonous action of excessive smoking upon the nervous system. The smoker is never quite free from a form of naso-pharyngitis and, sooner or later, a mild chronic tracheitis appears. Langmaid thinks the morning cough due thereto characteristic, as he has frequently found it disappear upon the suspension of tobacco-smoking. He specially draws attention to the effect of tobacco upon the singing voice. Macleod Yearsley. 